\title{
Kinship and colour terms in Mexican Sign Language
}

\author{
Bernadet Hendriks
}

\section{Introduction}

Mexican Sign Language (Lengua de Señas Mexicana, LSM) is a natural sign language used by an estimated $100,000+$ Deaf people in Mexico. It is used mainly in urban areas. There are large Deaf communities in the three biggest cities of Mexico (Monterrey in the North with over 1 million inhabitants, Guadalajara in the West with 4,5 million inhabitants, and Mexico City, which is considered Central Mexico, with over 20 million inhabitants). In rural areas many Deaf people do not know LSM nor any other sign language, instead using a kind of home sign system. In the extreme South and East of the country (Yucatán peninsula and Chiapas, areas in which Maya is the traditional language), an indigenous Mayan sign language can be found. This sign language is referred to as Lengua de Señas Maya (LSMy) and is totally unrelated to LSM (cf. Shuman 1980; Shuman \& Shuman 1981; Johnson 1991; Fox-tree 2009).

LSM has little regional variation. Faurot, Dellinger, Eatough and Parkhurst (1999) conclude that LSM is one unified language, although not completely uniform. Their conclusion is based on lexical studies by Bickford (1991) and Smith-Stark (1986) which give a lexical similarity rate of $80-90 \%$ between various parts of the country, as well as their own personal interviews with Deaf Mexicans who told them that they had no difficulty understanding Deaf people from other cities. On the other hand, considerable variation between generations can be found in LSM, in particular in Mexico City (Bickford 1991). The difference in signing between older and younger signers may be such that they have problems understanding each other.

LSM is said to be derived from Old French Sign Language, like its neighbour ASL, albeit via a different route. The first mention of education for the Deaf in Mexico is found in a newspaper advertisement from 1821, announcing the intention of "a Spanish subject" who wants to receive Deaf and mute people from both sexes into his house to teach them "writing, intelligence and speaking" (Jullian 2001:52). Nine years later, in 1830, the official register of the government of the United States of Mexico mentions the arrival 


\section{Bernadet Hendriks}

of a French man called P.J. Roger "deaf and mute from birth" who intended to establish the first school for the Deaf in Mexico (Jullian 2001:52-53). Although almost nothing is known about these two people and their work, these records indicate that there was both Spanish and French influence in the very early stages of education for the Deaf in Mexico.

The person who is traditionally credited with bringing Deaf education and sign language to Mexico, however, is Edouard Huet, another Deaf man from France. He had been educated in the school of Abbé de L'Epée and had directed a school for the Deaf in Bourges, France. Subsequently he had emigrated to Brazil where he founded the "Imperial Institute for Deaf-mute" in Rio de Janeiro. He then moved to Mexico, where he arrived in 1866 to become the first director of the Escuela Municipal de Sordomudos (Municipal School for Deaf-mute), later known as Escuela Nacional de Sordomudos (National School for Deaf-mute). This school opened in June 1866 with three students (Jullian 2001:64). Until 1886 the curriculum was taught in sign language. The school closed in 1967, but is still considered to have been foundational in the establishment of a Deaf community in Mexico and in the development of LSM.

LSM, then, appears to be related to French Sign Language (LSF) and ASL. Indeed, a number of cognates in basic vocabulary can be found between these sign languages (cf. Smith 1986, 1990; Guerra Curry, Meier and Walters 2002 for LSM and LSF; Quinto-Pozos 2008 for ASL and LSM). According to Smith 1990 there is also a clear relationship between Brazilian Sign Language (LIBRAS) and LSM, which can be attributed to the fact that the same person was responsible for the foundation of the first national institute for the Deaf in both countries. It would seem, then, that the influence of Edouard Huet was indeed considerable in the development of LSM. Despite these relationships, however, LSM is not mutually intelligible with either modern LSF (cf. Smith 1990), ASL (cf. Smith Stark 1986, 1990; Faurot et al. 1999; Quinto-Pozos 2008) or LIBRAS. Likewise, although the influence of Spanish in LSM is relatively strong (as can be seen by the frequency of initialisation, see below) and the very first person who was apparently involved in Deaf education in Mexico was Spanish, LSM and Lengua de Señas Española (LSE) are mutually unintelligible. Indeed, Guerra Curry, Meier and Walters (2002) find no clear examples of borrowing from LSE into LSM.

Although a fair number of linguistic studies into LSM have been undertaken over the past decades, most of these have been in Spanish, and are not very well known on an international level (e.g. Smith 1986, Cruz 2008). An exception is a doctoral thesis in English by Fridman, published in 2010, dealing with tense and aspect inflections in LSM. The present chapter will 
describe some aspects of the lexical domains of kinship and colour in LSM, focusing on the influence of Spanish in these domains.

Data for this chapter was collected from published dictionaries of LSM, as well as two Deaf Mexicans (a mother and her daughter from Mexico City), who were videotaped using the elicitation materials described in Sagara \& Zeshan, this volume. ${ }^{1}$

\section{Lexical families of kinship terms in LSM}

Kinship terms in LSM are to a large extent influenced by Spanish, both lexically and phonologically. In particular, the gender system of Spanish is to a certain degree reflected in the LSM kinship system. Spanish has inherent gender; all words are either masculine (as a rule ${ }^{2}$ ending in $-O$ for singular and $-o s$ for plural) or feminine (as a rule ending in $-a$ for singular and - as for plural). The masculine ending is also the unmarked form. For instance, if a person is pregnant and wants to refer to the baby without knowing its gender, the word niño 'child' (masc.) is used. Similarly, a mixed gender group of people is referred to with the masculine plural ending. LSM differs from Spanish in not having inherent gender. Instead, most kinship terms in LSM are unspecified for gender. Semantically, however, these unspecified forms resemble the unmarked masculine form in Spanish. Thus, LSM has signs for HIJO 'offspring', HERMANO 'sibling', SUEGRO 'parent-in-law', $A B U E L O$ 'grandparent', NIETO 'grandchild', ESPOSO 'spouse' etc., a few examples of which are shown in Figures 1-3.

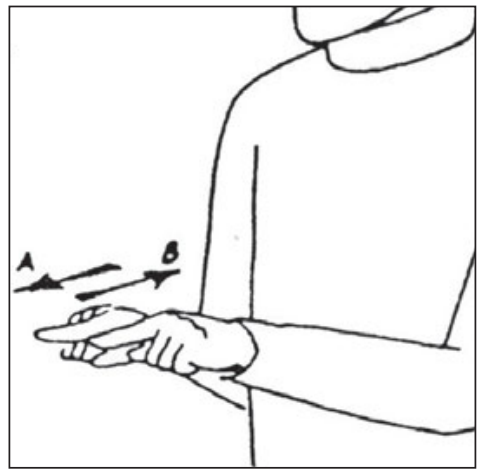

Figure 1. HERMANO

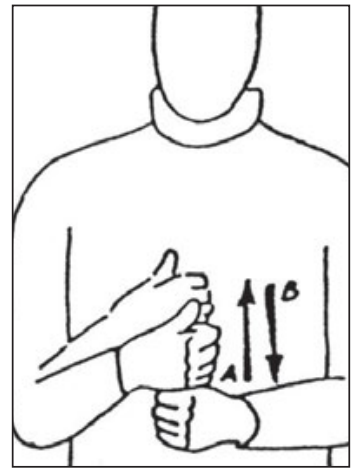

Figure 2. ABUELO

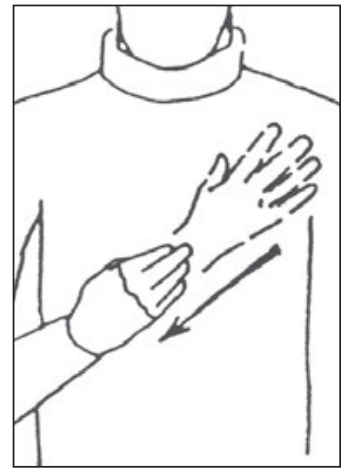

Figure 3. HIJO

These unmarked forms can be used to refer to either males or females, depending on the context. However, if reference is made to a female, 
and this cannot be inferred from the context ${ }^{3}$, the sign MUJER 'woman' (cf. Figure 10) or a special feminine suffix -FEM (a B-hand with the palm down making a downward movement in neutral space) is often added. In such cases the unspecified sign on its own would normally be interpreted as being masculine. There are a few exceptions to this rule. In particular, the signs for $M A M A$ ' $M o m$ ' (also used in the sense of 'mother' although there is a separate sign for the word madre) and $P A P A$ ' 'Dad' (also used in the sense of 'father') do inherently express gender, as shown in Figures 4 and 5. The concept of mother, then, cannot be expressed by signing $P A P A$ and using the word MUJER or the feminine suffix.

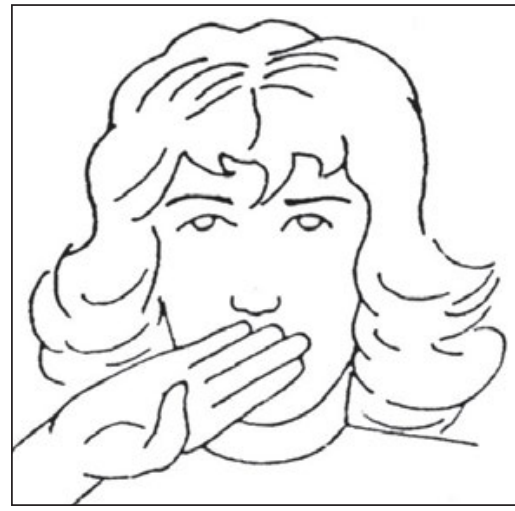

Figure 4. $M A M A ́$

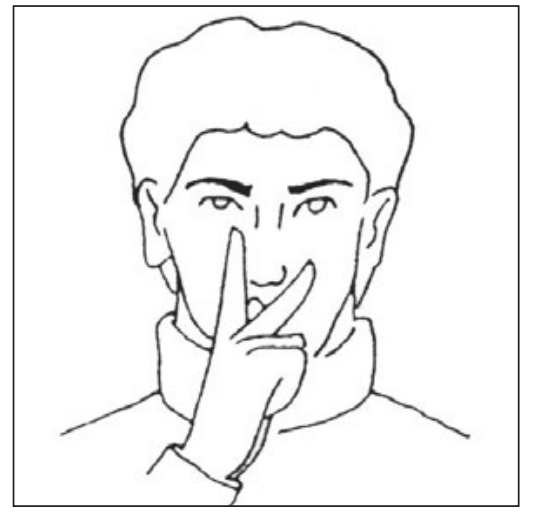

Figure 5. $P A P A ́$

In Spanish, equally, the words for mamá and papá and the words padre 'father' and madre 'mother' express gender within the stem, rather than by means of a suffix. Similarly, signs that are morphologically related to these forms, such as MADRINA 'godmother' and PADRINO 'godfather' (both important pseudo-kinship terms in Catholic Mexico) also express gender within the stem.

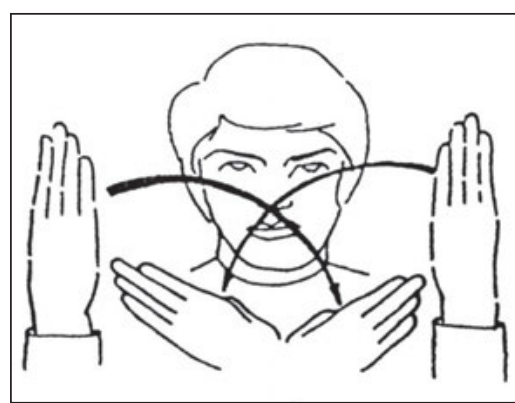

Figure 6. MADRINA

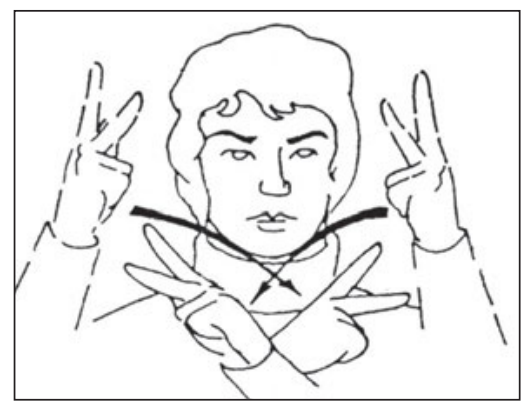

Figure 7. PADRINO 
A difference between Spanish and LSM in these terms is that Spanish uses the plural of the masculine word padre, namely padres to refer to both parents, whereas LSM uses a compound made up of the two signs $P A P \dot{A}^{\wedge} M A M \dot{A}^{4}{ }^{4}$

Within the paradigm of members of the extended family, there is one more pair of kinship terms with inherent gender in both Spanish and LSM, namely the pair NUERA 'daughter-in-law' (Figure 8) and YERNO 'son-in-law' (Figure 9), for which there is no encompassing term meaning 'spouse of offspring'. The fact that this idiosyncrasy in the paradigm of the extended family occurs both in Spanish and in LSM demonstrates the influence of Spanish on the LSM paradigm.

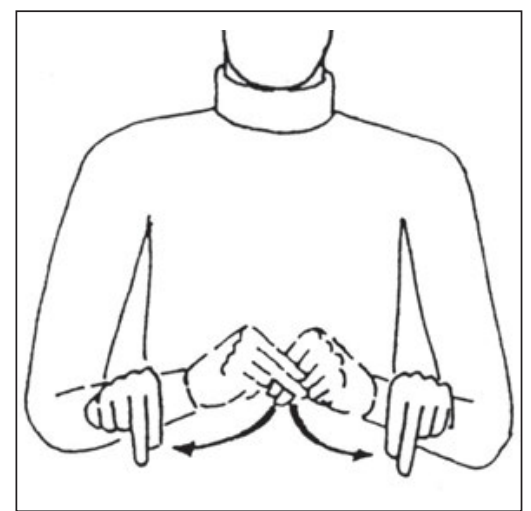

Figure 8. NUERA

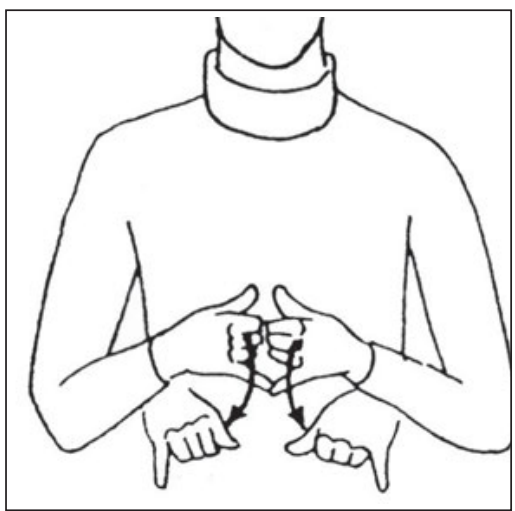

Figure 9. YERNO

A difference between the gender system of Spanish and LSM within the kinship paradigm is the way in which the feminine marker is expressed. Whereas in Spanish the masculine/ unmarked suffix is replaced by a feminine suffix for every occurrence of the word, in LSM the specification MUJER 'woman' (cf. Figure 10) is usually added after the sign is introduced. If a person has already been introduced and his or her gender can be inferred from the context, it is not necessary to keep adding MUJER every time the sign occurs. The unmarked form can take on feminine meaning if the context requires. The same goes for the feminine marker which I have glossed $-F E M$. This marker is treated here as a suffix because it cannot occur on its own. According to an unpublished paper by Dufoe (2008) the -FEM suffix appeared in the early eighties and seems to be based on the second part of the sign SEÑORA 'Mrs.', which is SEÑOR 'Mister' followed by something very similar to the feminine suffix, as shown below in Figures 11 and 12. The sign SEÑORA is certainly older than the $-F E M$ suffix, and in contrast to it, is used by Deaf children of Deaf parents and Deaf people of 50 years 
and older, most of whom do not use the $-F E M$ suffix and do not consider it acceptable LSM. Among young signers, however, the $-F E M$ suffix is in frequent use, and for some signers has largely replaced the older construction using MUJER. According to Cruz (2008:483), on the other hand, the feminine suffix is mainly used in the educational system and is replaced more and more by the compounded form with MUJER. Dufoe (2008) also mentions that the feminine suffix cannot be used with all animate nouns and is used almost exclusively with kinship terms. The feminine suffix in Spanish, on the other hand, is not only used for animate beings, but also with inanimate nouns, and is a general feature of Spanish grammar since all nouns in Spanish are either masculine or feminine.

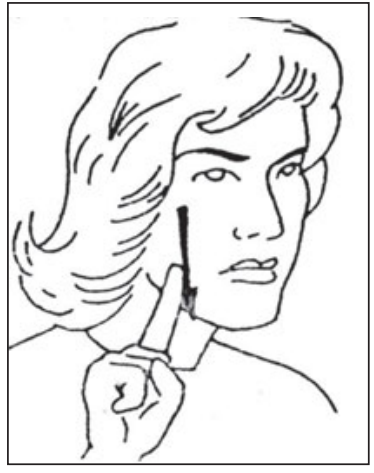

Figure 10. MUJER

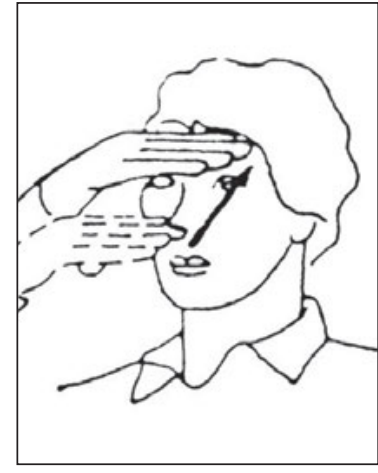

Figure 11. SEÑOR

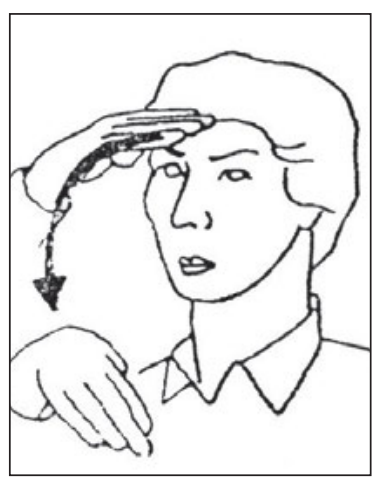

Figure 12. SEÑORA

Phonologically, most kinship terms use a handshape derived from the LSM fingerspelling alphabet (which is shown in Figure 13) ( $^{5}$ representing the first letter of the corresponding Spanish word. This is referred to as initialisation.

Initialisation is an extremely pervasive phenomenon in the LSM lexicon. A count of initialised signs in various LSM dictionaries shows that about $30 \%$ of the LSM basic lexicon is initialised. ${ }^{6}$ Initialisation being so pervasive, it is not viewed negatively by signers, as has been reported for ASL (cf. Padden 1998). Uneducated LSM signers with little knowledge of Spanish are often not aware of the fact that signs are initialised. More educated signers, although they are aware of initialisation, often comment that "this is simply the sign in LSM" (Shelley Dufoe: personal communication). Hendriks and Dufoe (2014) argue that initialised signs form part of the core vocabulary of LSM. In LSM, many lexical families of initialised signs can be found. Lexical families is a term used for "groups of signs with a common correspondence between phonological form and meaning" (Fernald and Napoli 2000:5), involving variation in only one of the four 
Kinship and colour terms in LSM 339

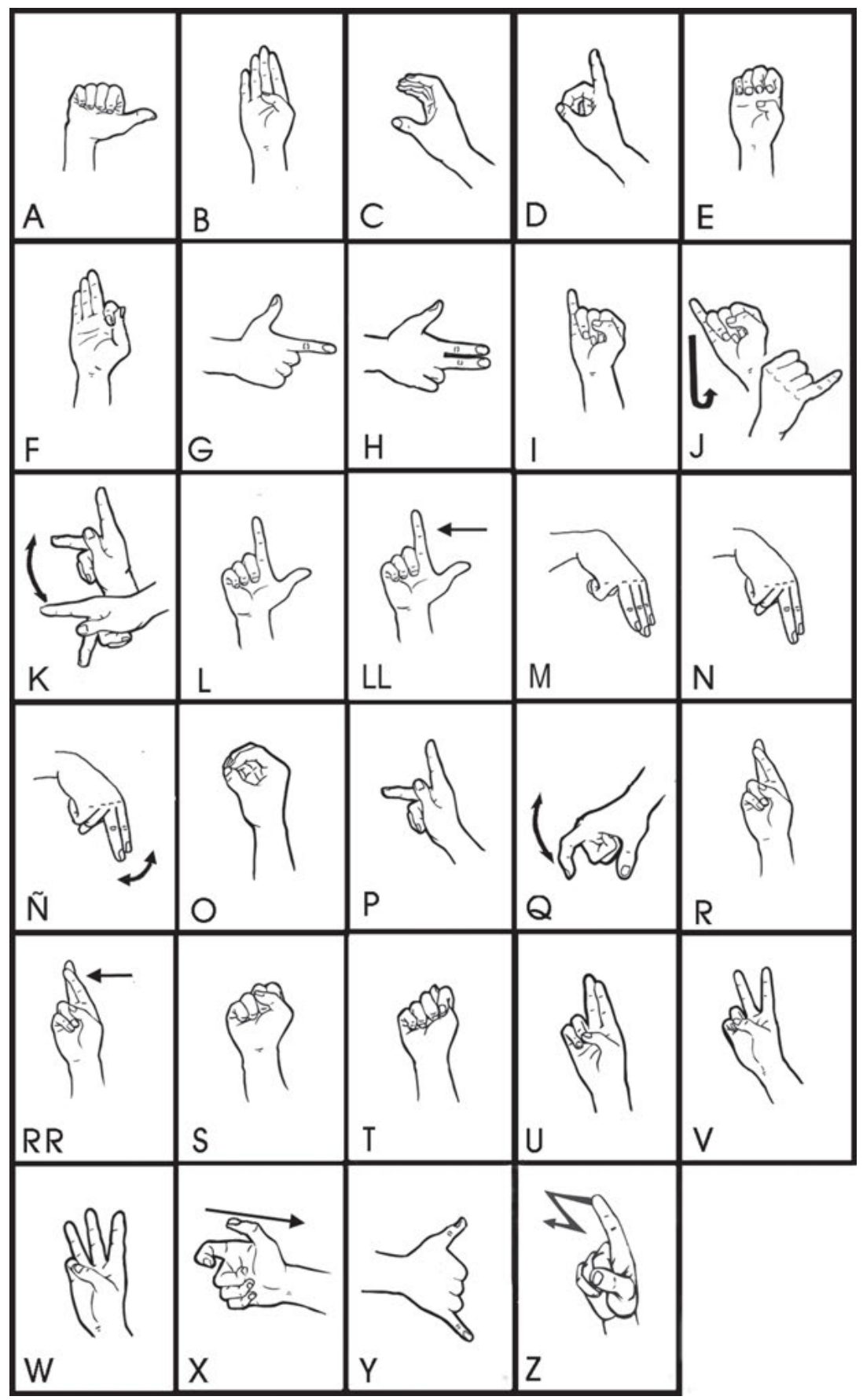

Figure 13. The fingerspelling alphabet used in Mexico 
parameters of handshape, place of articulation, movement or orientation. Lexical families based on initialisation are groups of signs that share the same place of articulation, movement and orientation, but differ in the (initialised) handshape.

There are four basic kinship terms for in-laws in LSM, which are shown in Figure 14. The signs SUEGRO 'parent-in-law' and CUÑADO 'sibling-in-law' are gender-neutral, the signs YERNO 'son-in-law' and NUERA 'daughter-in-law' are specified for gender, as indicated above. These four signs form a lexical family based on initialisation. All four signs are two-handed and have the same orientation, movement and place of articulation. Only the handshapes differ, and these represent the first letter of the corresponding Spanish word.

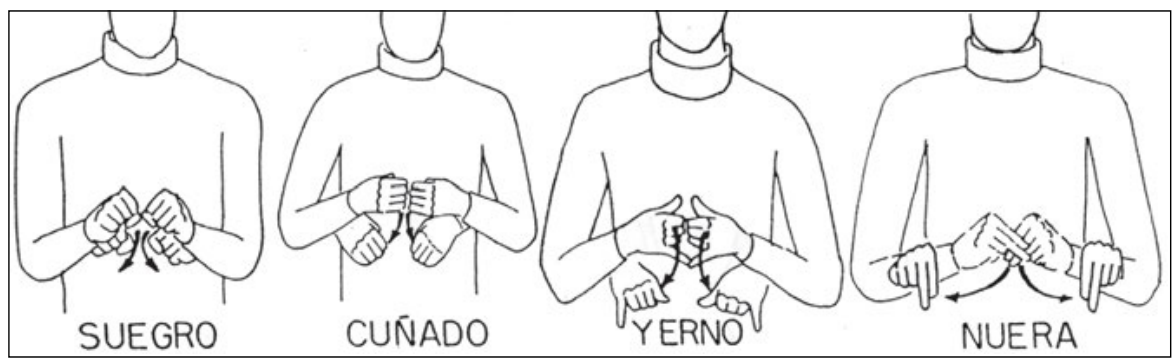

Figure 14. lexical family of in-laws

In the same way, the signs for $P A P A$ and $M A M A \dot{A}$ (cf. Figures 4 and 5) and the signs PADRINO and MADRINA (cf. Figures 6 and 7) make up lexical families of two members. In fact, so strong is the tendency in LSM to create lexical families based on initialisation that most dictionaries of LSM, including the López et al. (2006) dictionary, which usually tries to avoid initialisation, show both MAMÁ and MADRINA as initialised signs using the modern M-handshape. However, a number of middle aged and older signers have commented that these were originally made with a B-handshape, as shown in Figures 5 and 7, and that they feel initialisation has been imposed on them. In fact, the original M-handshape in the LSM alphabet (just as in the modern LSF fingerspelling alphabet) was very similar to a B-handshape. Thus, it would seem that these signs in their original form were already initialised, but since the initialisation was no longer apparent after the handshape in the fingerspelling alphabet changed, they have been $r e$-initialised using the newer handshape, although the older form is also still in use.

The kinship terms for the non-core family members PRIMO 'cousin', SOBRINO 'child of sibling', a variant of $T I^{\prime} O^{7}$ 'sibling of parent' and 
NIETO 'grandchild' also form a lexical family (cf. Figure 15), although the movement of NIETO tends to be slightly different to that of the other three members of the family. Thus, NIETO can be said to form an extended family with the other three terms (cf. Section 3 for an explanation of the term extended family). In fact, the only basic kinship term for a non-core family member that does not fit into the lexical family is the sign $A B U E L O$ 'grandparent', shown in Figure 2.

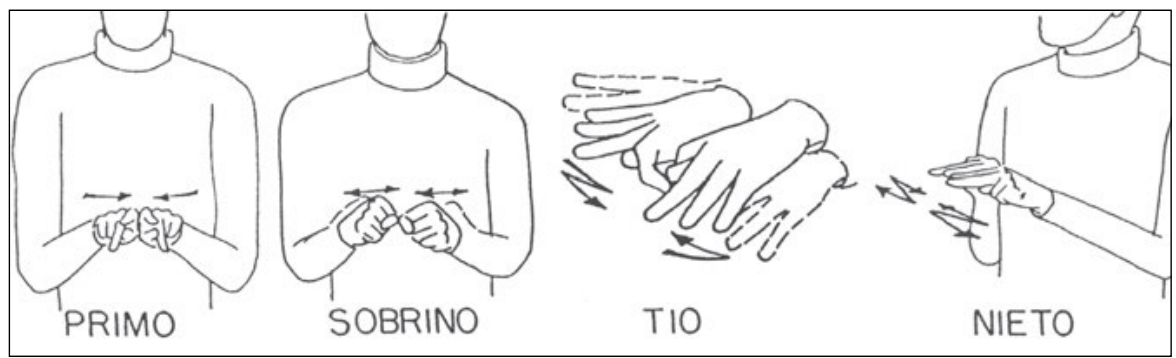

Figure 15. Lexical family of non-core family members

Apart from the signs that have been shown so far, there are also compound signs that denote non-basic non-core family relations, such as $B I S^{\wedge} A B U E L O$ 'greatgrandparent', TARTA^ABUELO 'great-great-grandparent', $B I S^{\wedge} N I E T O$ 'great-grandchild', $C O N^{\wedge} C U N \tilde{N} O$ 'spouse of sibling-in-law', $C O N^{\wedge} S U E G R O$ 'parent of son/daughter-in-law'. The signs for BIS and TARTA are initialised, and occur only as the first component part of kinship terms. The sign $C O N$ is a sign that is also used outside of the kinship paradigm and is not initialised.

LSM, then, shows a great deal of Spanish influence on the kinship system, both lexically and, more indirectly, phonologically because of initialisation. Lexically, LSM uses the same kinship terms as Spanish, including irregularities, such as the fact that all terms for in-laws have non-gendered stems except for YERNO 'son-in-law' and NUERA 'daughter-in-law'. Although not all kinship signs are initialised, and most core family terms, such as sibling and offspring (as shown in Figures 1 and 3) are uninitialised, initialisation is extremely common in kinship terms, and there are several lexical families of kinship terms. In some cases (re-)initialisation has been forced on kinship terms that albeit originally initialised no longer appeared initialised because of a handshape change in the manual alphabet, to make them fit better into a lexical family based on initialisation, as is the case with $M A M A ́$ and MADRINA. In these cases, however, the older, uninitialised variant continues to be used as well. For older signers and most native signers (Deaf children of Deaf parents) in particular, these older signs are more acceptable. 


\section{The influence of Spanish on colour terms in LSM}

Like kinship terms, colour terms in LSM have been influenced by Spanish, both in the distinctions made between colours, as well as in the form of many of the signs. LSM has signs for the basic colours that occur in Spanish, such as green, blue, yellow, red, orange, brown, purple, pink, grey, as well as black and white. Signs denoting metals with a specific colour, such as bronze, copper, gold and silver can also be used to signify the corresponding colours, just as in Spanish. Moreover, some modifications that are used to describe colours in more detail are the same as those used in Spanish. Thus, the sign VERDE 'green' can be modified by the sign MILITAR 'military' to describe the colour used in military uniforms. Likewise, the sign for $A Z U L$ 'blue' can be modified by the sign $R E Y$ 'king' to describe the colour royal blue, and ROJO 'red' can be modified by VINO 'wine' to describe the colour wine-red. The latter colour can also be signed as COLOR 'colour' VINO. Moreover, in LSM, just as in Spanish, the sign for the colour $C A F E$ ' 'brown' is a homonym with the drink $C A F E$ ' 'coffee' and the sign for the colour $N A R A N J A^{8}$ 'orange' is the same as the sign for the fruit NARANJA 'orange'. The modifiers CLARO 'light' and OSCURO 'dark' are used in LSM and Spanish in more or less the same way as well, although one of the LSM informants appeared to use the sign CLARO in two different ways depending on her facial expression. She signed $C L A R O$ with a neutral facial expression to indicate a light colour, but signed $C L A R O$ with her tongue protruding to denote a bright colour. Indeed, in Spanish the word claro can mean both bright and light, but in the context of colours normally has the meaning 'light'.

As far as the phonological form of colour signs is concerned, most colour signs, like most kinship terms, are initialised. There are only a few basic colour signs that are not initialised. These are ROJO 'red', which is iconic in that it denotes the red of the lips (Figure 16) ${ }^{9}, N A R A N J A$, which is a homonym with the sign for the fruit, as in Spanish (Figure 17) and MORADO 'purple', which appears to be an arbitrary sign in that it is non-iconic and not related to Spanish (Figure 18).

The signs VERDE, NEGRO, AZUL, AMARILLO, BLANCO, ROSA, $G R I S$ and $C A F E$ are all initialised and have the non-dominant hand as place of articulation.

The initialised basic colour terms in LSM are all part an extended lexical family. This term is used by Fernald and Napoli (2000) for signs that are semantically related but differ in more than one phonological parameter. There are four colour signs that share the same place of articulation and the same movement, namely a back-and-forth rubbing movement on the palm 


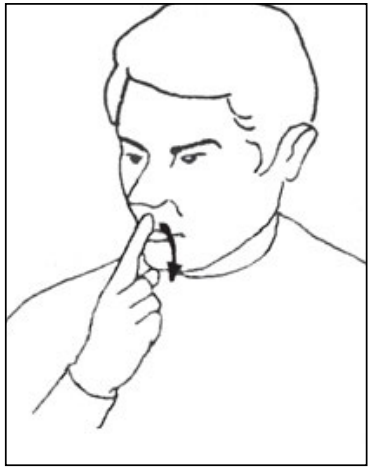

Figure 16. ROJO

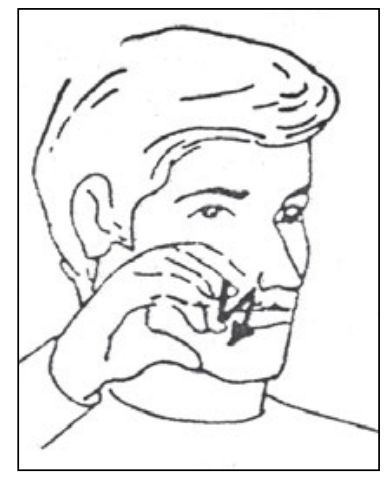

Figure 17. NARANJA

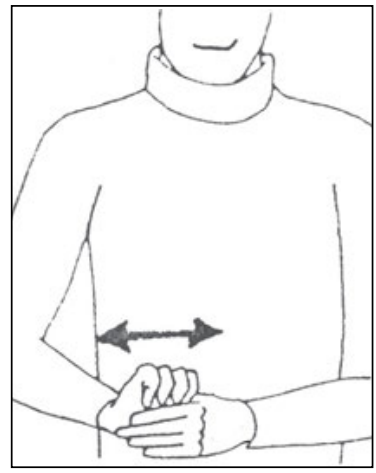

Figure 18. MORADO

of the non-dominant hand (VERDE 'green', ROSA 'pink', and GRIS 'grey' and one variant of $B L A N C O$ 'white'). However, the orientation of these signs may differ, $V E R D E$ being produced with the palm down (Figure 19), ROSA and GRIS with the palm to one side and BLANCO with the palm up. Other items that belong to the same extended family have a slightly different movement. $N E G R O$ 'black' and another variant of $B L A N C O$, for instance, have only a single rubbing movement towards the fingertips of the non-dominant hand, as shown in Figure 20. AZUL 'blue' is also made with a rubbing movement on the non-dominant palm, but this sign is made by most people with a circular movement, apparently to produce a greater contrast with AMARILLO 'yellow' which has the same handshape but is made with a back-and-forth rubbing movement on the back of the non-dominant hand, $\mathrm{cf}$. Figure 21. Similarly, yet another variant of $B L A N C O$ is made on the back of the non-dominant hand. The colour $C A F E^{\prime}$ 'brown' which is both initialised and a homonym with the drink $C A F E$ ' 'coffee' is made on the side of the index of the non-dominant hand with either a back-and-forth or a circular movement (cf. Figure 22).

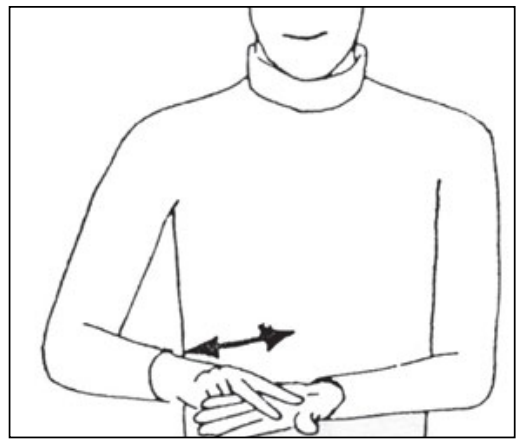

Figure 19. VERDE

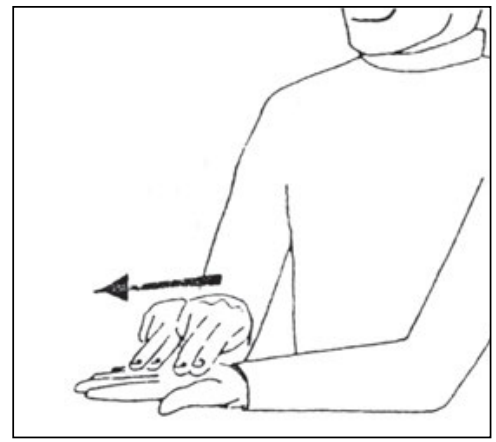

Figure 20. NEGRO 


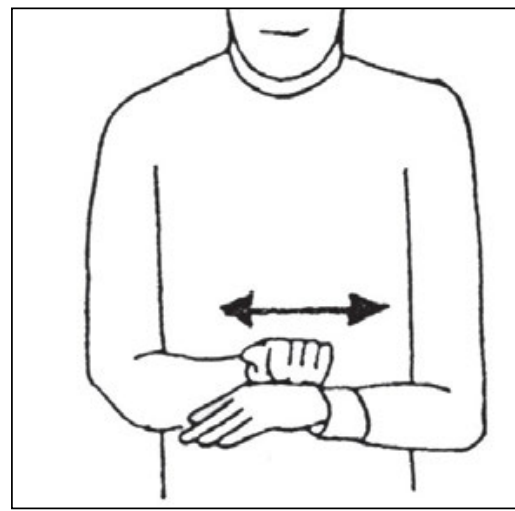

Figure 21. AMARILLO

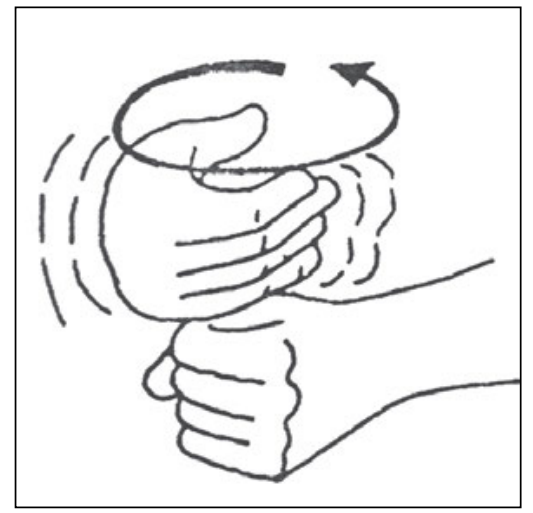

Figure 22. $C A F \dot{E}$

Thus, although $V E R D E$ and $C A F E$ differ from each other in handshape and orientation, as well as the orientation of the non-dominant hand, which functions as the place of articulation, they can still be considered members of the same extended family, because of their semantic relatedness and because of the other colour terms with which they share phonological parameters. $C A F E$, for instance, shares its orientation with GRIS, which in its turn shares the orientation of the non-dominant hand with VERDE.

When it comes to describing colours, especially colours that only differ slightly, in detail, Deaf informants use different strategies than hearing Mexicans. Two hearing informants who were asked to describe the colour strips in the elicitation materials were more likely to use a particular colour term with a modifier and hardly ever used more than two words to describe a particular colour, whereas two Deaf informants used longer descriptions likening the colour to a certain object, or described a specific colour as a mix of two different more basic colours. Thus, whereas the hearing informants described a specific colour brown (colour strip 6) as simply café claro 'light brown' or ocre 'ocher', two Deaf informants likened the colour to that of furniture. Their descriptions are given in (1) and (2):

$\begin{array}{lllllll}\text { (1) COLOR } & \text { CAFÉ } & \text { IGUAL MESA } & \text { SILLA CAFÉ MÁS } & \text { CLARO } \\ \text { colour brown same table chair brown more light } \\ \text { 'the colour brown, like a table or chair, a lighter brown' }\end{array}$




$\begin{array}{lllll}\text { MAS-O-MENOS } & \text { COMO } & \text { PARECER } & \text { MIRAR } & \text { CATÓLICO } \\ \text { more-or-less } & \text { like } & \text { appear } & \text { look } & \text { Catholic } \\ \text { IGLESIA } & \text { MISA } & \text { ALTAR } & \text { COLOR } & \text { CARACTER IGUAL } \\ \text { church mass altar } & \text { colour } & \text { characteristic-of same } \\ \text { ADENTRO CAFE } & \text { ESO } & \text { IGUAL } & \text { COLOR } \\ \text { inside } & \text { brown that } & \text { same } & \text { colour }\end{array}$

'It's the colour brown characteristic of tables, it's not light or dark, a little light maybe, like the colour you also characteristically see inside a Catholic church at mass, of the altar, that same colour brown.'

Likewise, a specific colour dark yellow (colour strip 27) was described by both hearing informants as amarillo mostaza 'mustard yellow', but the two Deaf informants both said it was a mix of yellow and orange:

$\begin{array}{lllll}\text { AMARILLO } & \text { PARECE } & \text { NARANJA } & \text { MITAD MÁS ABRIR-NARANJA } \\ \text { yellow appear orange } & \text { half more open-orange } & \text { or } \\ \text { POCO ESO-Y-ESO } & \text { NARANJA } & \text { MÁS-O-MENOS } & \text { MITAD } \\ \text { a-little this-and-that orange } & \text { more-or-less } & \text { half } \\ \text { ABRIR-NARANJA } & \text { NARANJA } & & \\ \text { open-orange } & \text { orange } & & \end{array}$

'It's yellow but it looks like the inside of an orange, it's more or less orange, a little of this and a little of that, more or less orange, like the inside of an orange.'

(4) COLOR AMARILLO PERO MÁS OSCURO CON POCO NARANJA colour yellow but more dark with a-little orange OSCURO AMARILLO POCO IGUAL SOL MAÑANA AMANECER dark yellow a-little same sun morning rise PARECE SALIDA-SOL SOL ESO COMO COLOR AMARILLO similar-to sunrise sun that like colour yellow MÁS-OSCURO MÁS-O-MENOS more-dark more-or-less

'It's the colour yellow, but darker with a little bit of orange, dark yellow, a little like the sun when it comes up in the morning at dawn, that sun is more or less like this colour yellow, a bit darkish.'

Thus, apart from the Deaf informants being more specific in their descriptions than the hearing informants, it seems that LSM has fewer standard expressions to describe nuances in colour terms than Spanish and lacks some of the non-basic colour terms that Spanish has such as ocre 'ocher' and violeta 'violet'. Deaf informants do fingerspell the non-basic colour term $L-I-L-A$ ('lilac'), usually in combination with the sign MORADO 'purple'. 
As far as colour terms are concerned, then, LSM shows influence of Spanish both at the lexical and the phonological level. Phonologically, most colour terms are derived from their Spanish equivalent by means of initialisation. For basic colours terms there is a one-to-one correspondence between Spanish words and signs in LSM. If we take a more detailed look, however, we do find differences. Thus, LSM lacks some of the more precise colour terms that Spanish uses (or at least they are not standardised) and signers tend to use elaborate descriptions to distinguish colours that are similar.

\section{Conclusion}

Although LSM is a well-developed natural sign language, that appears to go back at least to 1866, when the first school for the Deaf was established in Mexico City, it shows strong influences from Spanish, both at the lexical and the phonological level. At the lexical level, there is a one-to-one correspondence between the kinship system in LSM and its Spanish counterpart. The same is true for basic colours in LSM and Spanish, although Spanish has more specialised words to express non-basic colours than LSM. The most striking influence of Spanish, however, is the quantity of initialised signs within the LSM lexicon. A complete analysis of initialisation in LSM is beyond the scope of this chapter, but cf. Hendriks and Dufoe (2014) for a more in-depth study of initialisation and the position of initialised signs in the LSM lexicon. This chapter has focused on initialisation in the kinship and the colour system. In both these systems the majority of signs have handshapes derived from the fingerspelling alphabet, expressing the first letter of the corresponding Spanish word. Both kinship and colour terms in LSM can be grouped into lexical families based on initialisation. In fact, initialised basic colour terms all form an extended lexical family, as defined by Fernald and Napoli (2000). Although some initialised signs have uninitialised counterparts and initialisation appears to have been imposed on these signs over the last decades (usually by hearing people), most initialised signs do not have uninitialised counterparts and are completely accepted by Deaf people. This suggests that initialisation is a phenomenon that has been part of LSM since the origins of the language. 


\section{Notes}

1. Because no permission was given to use the videotaped materials in this book, only illustrations from published dictionaries could be used. All illustrations in this article, except for the fingerspelling alphabet in Figure 13, have been taken from Miranda (1997), with permission.

2. This is a general rule for adjectives, and it also holds for many nouns, but there are many exceptions in the nominal system.

3. The context can either be real life context or discourse internal context. If a signer stands next to her sister she can sign IX MI HERMANO 'that is my sibling' without specifying gender, because the gender is visible to the observer, and is therefore clarified by the real life context. Similarly, in the story of Little Red Riding Hood, when the grandmother is first introduced, she may be referred to as ABUELO MUJER 'grandmother woman' or ABUELO -FEM but once her gender is established, she is subsequently referred to simply as ABUELO 'grandparent'. In this case it is discourse internal context that renders further gender specifications redundant.

4. Normally both MAMÁ and PAPÁ are made with a double contact on the chin, but the movement in the compound is reduced; both parts of the compound only contact the chin once.

5. Apparently, the original LSM fingerspelling alphabet was largely derived from the Old French fingerspelling alphabet, with some Spanish letters added. Over the years, however, certain handshapes, such as the H-handshape, the M-handshape, and the T-handshape have changed. LSM has both examples of initialised signs using the older handshapes, and initialised signs using the newer handshapes. Thus, for example, the sign TRABAJAR 'work' uses the old T-handshapes, whereas the sign TÍTULO 'title' uses the new T-handshape. This indicates that TRABAJAR is an older sign than TÍTULO, which apparently has been adopted into the language more recently (cf. Hendriks and Dufoe, forthcoming).

6. The percentage is an average taken from three different dictionaries $(33 \%$ in Serafín 1990, 31\% in Miranda 1997, and 28\% in López, Rodríguez, Samora and San Esteban 2006).

7. There is another variant, namely fingerspelled T-Í-O 'uncle' or T-Í-A 'aunt'. Note that the initialised form uses the old T-handshape with non-selected fingers extended, which is no longer used in fingerspelling and has been replaced by the modern T-handshape shown in the fingerspelling alphabet in Figure 13 (cf. also note 5). 
8. Note that this colour can be referred to as both naranja and anaranjado in Spanish. LSM has only one sign.

9. One of the informants, a Deaf child of Deaf parents, signed this sign with the R-handshape the very first time she produced it during the elicitation session. Afterwards she went on to use the non-initialised sign in Figure 16. ROJO is not depicted as an initialised sign in any of the dictionaries of LSM, and I have not seen it used on any other occasion.

\section{References}

Bickford, Albert. 1991. Lexical Variation in Mexican Sign Language: One Language or Many? Sign Language Studies 72: 241-276.

Cruz Aldrete, Miroslava. 2008. Gramatica de la Lengua de Señas Mexicana [Grammar of Mexican Sign Language]. PhD. Diss., El Colegio de México, México D.F.

Faurough, Karla, Dianne Dellinger, Andy Eatough and Steven Parkhurst. 1999. The identity of Mexican Sign as a language. SIL Electronic survey reports, no. 2000-002.

Fernald, Theodore B., and Donna J. Napoli. 2000. Exploring of Morphological Possibilities in Signed Languages. Sign Language and Linguistics 3: 3-58.

Fox Tree, Erich. 2009. Meemul Tziij: An Indigenous Sign Language Complex of Mesoamerica. Sign Language Studies 9: 324-366.

Fridman Mintz, Boris. 2010. Tense and Aspect Inflections in Mexican Sign Language Verbs. Saarbrücken: Lambert Academic Publishing.

Guerra Currie, Anne-Marie, Richard Meier, and Keith Walters. 2002. A crosslinguistic Examination of the Lexicons of Four Signed Languages. In Modality and structure in signed and spoken Language, Richard Meier, Kearsy Cormier, and David Quinto-Pozos (eds.), 224-236. Cambridge: Cambridge University Press.

Hendriks, Bernadet and Shelley Dufoe. 2014. Non-native or Native Vocabulary in Mexican Sign Language. Sign Language \& Linguistics, 17 (20-55).

Johnson, Robert E. 1991. Sign Language, Culture \& Community in a Traditional Yucatec Maya Village. Sign Language Studies 73: 461-474.

Jullian Montañez, Christian G. 2001. Génesis de la comunidad silente en México [Genesis of the silent community in Mexico]. Licentiate Thesis. UNAM, México D.F.

López García, Luis A., Rosa M. Rodríguez Cervantes, María G. Zamora Martínez, and Susana San Esteban Sosa. 2006. Mis Manos que Hablan [My Hands That Speak]. México D.F.: Editorial Trillas 
Miranda, S., Juan Carlos. 1997. Lengua de Señas de México [Sign Language of Mexico]. México D.F.: Asociación Mexicana de Sordos.

Padden, Carol. 1998. The ASL Lexicon. Sign Language and Linguistics 1: 39-60.

Quinto-Pozos, David. 2008. Sign Language Contact and Interference: ASL and LSM. Language in Society 37: 61-189.

Serafín García, María E. 1990. Comunicación Manual, Tomo I [Manual Communication, Volume 1]. México D.F.: Secretaría de Educación Pública.

Shuman, Malcolm K. 1980. The Sound of Silence in Nohyah: A Preliminary Account of Sign Language Use by the Deaf in a Maya Community in Yucatan, Mexico. Language Sciences 2: 144-173.

Shuman, Malcolm K., and Mary M. Shuman. 1981. A Brief Annotated Sign List of Yucatec Maya Sign Language. Language Sciences 3: 124-185.

Smith Stark, Thomas. 1986. La lengua manual mexicana [The Mexican manual language]. Manuscript, El Colegio de México, México D.F.

Smith Stark, Thomas. 1990. Una comparación de las lenguas manuales de México $y$ de Brasil [A comparison between the manual languages of Mexico and Brazil]. Paper presented at the 9th International Congress of the Association for Linguistics and Philology in Latin America, Brazil. 
